\title{
Article
}

\section{The role of biomechanical analysis of horse and rider in equitation science}

Clayton, Hilary M. and Hobbs, Sarah Jane

Available at http://clok.uclan.ac.uk/17182/

Clayton, Hilary M. and Hobbs, Sarah Jane ORCID: 0000-0002-1552-8647 (2017) The role of biomechanical analysis of horse and rider in equitation science. Applied Animal Behaviour Science. ISSN 01681591

It is advisable to refer to the publisher's version if you intend to cite from the work. http://dx.doi.org/10.1016/j.applanim.2017.02.011

For more information about UCLan's research in this area go to

http://www.uclan.ac.uk/researchgroups/ and search for <name of research Group >.

For information about Research generally at UCLan please go to http://www.uclan.ac.uk/research/

All outputs in CLoK are protected by Intellectual Property Rights law, including Copyright law. Copyright, IPR and Moral Rights for the works on this site are retained by the individual authors and/or other copyright owners. Terms and conditions for use of this material are defined in the policies page. 


\section{Accepted Manuscript}

Title: The role of biomechanical analysis of horse and rider in equitation science

Authors: Hilary M. Clayton, Sarah-Jane Hobbs

PII: $\quad$ S0168-1591(17)30062-X

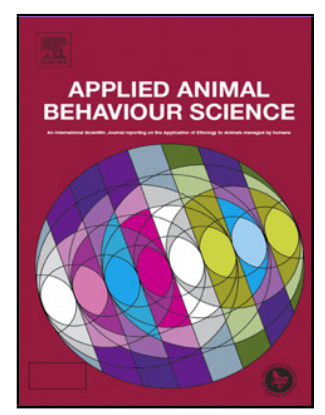

DOI: $\quad$ http://dx.doi.org/doi:10.1016/j.applanim.2017.02.011

Reference: $\quad$ APPLAN 4415

To appear in: $\quad$ APPLAN

Please cite this article as: Clayton, Hilary M., Hobbs, Sarah-Jane, The role of biomechanical analysis of horse and rider in equitation science.Applied Animal Behaviour Science http://dx.doi.org/10.1016/j.applanim.2017.02.011

This is a PDF file of an unedited manuscript that has been accepted for publication. As a service to our customers we are providing this early version of the manuscript. The manuscript will undergo copyediting, typesetting, and review of the resulting proof before it is published in its final form. Please note that during the production process errors may be discovered which could affect the content, and all legal disclaimers that apply to the journal pertain. 


\title{
The role of biomechanical analysis of horse and rider in equitation science
}

Hilary M. Clayton ${ }^{\mathrm{a},{ }^{*}}$ and Sarah-Jane Hobbs ${ }^{\mathrm{b}}$

${ }^{a}$ Sport Horse Science, 3145 Sandhill Road, Mason, MI 48854, US.

${ }^{b}$ University of Central Lancashire, Centre for Applied Sport and Exercise Sciences, Preston, UK

Corresponding author: Hilary M. Clayton, tel: +1 517333 3833, email:claytonh@cvm.msu.edu

\section{Research highlights}

Not applicable

\section{REVIEW PAPER}

\begin{abstract}
Equestrian sports are unique in that they involve the participation of two athletes that differ greatly in morphology yet are able to move together harmoniously; experienced riders not only move in phase with the horse, they can even improve the consistency of the horse's movements. The motion of the horse imposes perturbations on the rider that differ in magnitude and direction according to gait. In faster gaits where suspension phases are present, the rider must accommodate greater vertical and horizontal accelerations of the horse's trunk through threedimensional movements of their axial body segments. The rider, in turn, can improve the horse's performance through correct training, or cause it to deteriorate through faults in the rider's
\end{abstract}


position or incorrect application of the aids. This review addresses the current state of knowledge of the biomechanics of the horse-rider interaction, with reference to the ways in which the emerging field of equitation science can help to improve equine welfare by enhancing rider awareness of horse behaviour and movement, as well as the impact of the rider on the horse.

Keywords:Gaits Equestrian Rider Kinematics Equitation Science Welfare

\section{Introduction}

Equestrian sports involve two athletes whose movements should, ideally, be coupled seamlessly. Movements of the horse-rider dyad are driven by the horse and the novice rider should first learn to follow the horse's motion passively using coordinated movements of the rider's pelvis, trunk, head and limbs. This leads to the development of an independent seat which implies that the rider is dynamically stable and is capable of moving different parts of the body independently of each other. When this has been accomplished, the rider's kinematics become less variable (Peham et al., 2001) and the rider's movements are more closely matched with those of the horse (Lagarde et al., 2005). Only after becoming dynamically stable on the horse, can the rider develop the skills needed to influence the speed, direction and activity of the horse. In order to safeguard the welfare of the horse, the training program should adhere to the principles of equitation science. This review addresses the horse, the rider and the coupling between them at the basic gaits of walk, amble, trot, canter and gallop, where amble defines 4-beat stepping gaits such as tölt or running walk (Nicodemus and Clayton, 2003). Movements of the horse are considered with respect to how they affect the rider with the emphasis being on movements of the horse's trunk. Kinematics and dynamic stability of the rider are addressed in relation to the 
perturbations that are applied as a result of the horse's motion. Finally, the rider's influence on the horse and common errors in performance are discussed.

\section{Equine Gaits and Movements}

Quadrupeds coordinate their four limbs spatially and temporally to produce a range of gaits that are used across a range of speeds. As a species horses are versatile in terms of the variety of gaits performed (Hildebrand, 1985). Kinematic variables describing the limb coordination pattern and the duty factor, which is the stance duration of a limb expressed as a percentage of the stride duration, provide important information about the underlying gait mechanics. More specifically, gaits are classified according to the left-right symmetry of the limb movements and the presence or absence of suspension phases, both of which are relevant to understanding the interaction of horse and rider (Hildebrand, 1985; Clayton, 2004).

In a symmetrical gait the movements of the contralateral (fore and hind) limb pairs are equally separated in time and space so the left and right limbs move out-of-phase with each other. In these gaits the movements and forces transmitted to the rider should have a symmetrical biphasic pattern in each stride with the forces imposed on the rider in the two halves of the stride being mirror images of each other. However horses, like people, are seldom completely symmetrical on the left and right sides, so the two halves of each stride may not completely mirror each other. Asymmetries in movement patterns found in symmetrical gaits may be anatomical or functional in origin. Equine skeletal asymmetries have been recorded in long bone lengths (Watson et al., 2003; Malone and Davies, 2014a, b) and functional sidedness patterns 
have been recognized (e.g. Meij and Meij, 1980; Murphy et al., 2005). Dynamic asymmetries of movements and forces are often present (Van Heel et al., 2010; Wiggers et al., 2015). One of the challenges for gait analysts lies in establishing threshold levels to differentiate minor asymmetry due to innate sidedness from more severe asymmetries associated with lameness.

In the asymmetrical gaits the movements of one or both contralateral (fore, hind) limb pairs are separated by unequal time intervals so a short footfall interval alternates with a long footfall interval. By definition, the trailing limb contacts the ground first and is rapidly followed by contact with the ground of the leading limb. A longer period of time intervenes between contact of the leading limb and the next contact of the trailing limb. Another way of expressing this is to say that contacts of the trailing and leading limb pair (fore or hind) occur as a couplet. Both the ground reaction forces and the forces transmitted to the rider are asymmetrical, and this requires adaptive movements by the rider.

Gaits are also classified as stepping (walking) or leaping (running) according to whether the limb support sequence includes one or more suspension phases (Hildebrand, 1985; Clayton, 2004). Stepping gaits do not have a suspension phase and are easy for the rider to sit since there is little vertical motion of the horse's back. In the leaping gaits the horse is projected vertically into the suspension phases and the rider must learn to accommodate this motion to avoid bouncing against the saddle and exerting large forces on the horse's back. These two types of gaits employ different mechanisms for conservation of mechanical energy. Stepping gaits use an inverted pendulum mechanism that involves an exchange between potential energy, which is due to position above the ground, and kinetic energy, which is due to motion, of the horse's centre of mass to reduce the amount of muscular work needed for locomotion. In leaping gaits potential and kinetic energy are converted to elastic strain energy (energy stored during deformation) by 
elastic tissues in the limbs and trunk. The bouncing motion of the leaping gaits can be represented as a mass-spring model in which the inherent compliance of the limbs allows storage and release of elastic energy as a means of reducing the muscular work of locomotion (Biewener, 2006).

Regardless of the gait that is being performed locomotion involves translation and rotation. The horse's trunk translates and rotates in three dimensions that can be described relative to the real world in a frame of reference known as a global coordinate system. The global coordinate system consists of three two dimensional planes called the sagittal, dorsal and transverse planes, and three axes of rotation, known as the longitudinal, transverse and vertical axes (Figures 1 and 2). The movements of the horse's trunk, the saddle, and the rider's body are described in terms of their translations along the vertical, longitudinal and transverse axes and their rotations around these axes. The segments translate up and down (dorsal to ventral in the horse, superior to inferior in the rider) along the vertical axis under the influence of gravitational forces. Rotations around the vertical axis involve twisting movements, which are also referred to as yaw rotations to the left and right sides. The segments translate forward and backward (craniocaudally in the horse, anterioposteriorly in the rider) along the longitudinal axis. Roll rotations around the longitudinal axis involve leaning from side to side and are described according to the direction of motion (left, right) of the upper part of the segment relative to the lower part. The segments translate from side-to-side (left to right) along the transverse axis. Pitch rotations around the transverse axis are described in terms of the direction of movement of the cranial (horse) or superior (rider) part of the segment relative to the caudal (horse) or inferior (rider) part. Pitch is described as nose up/nose down in the horse or posterior/anterior in the rider. When the horse and rider are viewed in the sagittal plane (as seen from the side) flexion and extension of the 
spine and pitching motions of the axial body segments are evident. Due to the vertical orientation of the axial body segments of the rider compared with the horizontal orientation of the axial body segments of the horse, different movements are seen in the two athletes in the frontal and transverse planes. In the frontal plane (as seen from in front or behind) lateral bending of the rider and twisting of the horse are seen. In the transverse plane (as seen from above or below) twisting of the rider and lateral bending of the horse are evident.

Kinematics are usually studied using either motion capture (mocap) systems or inertial measurement units (Hobbs et al., 2010; Clayton, 2013). Mocap systems track the movements of specific anatomical landmarks over time then use the coordinate data to calculate linear and angular displacements, velocities and accelerations. Inertial measurement units use accelerometers and gyroscopes to measure acceleration and orientation, from which velocities and displacements can be derived. In the context of equitation analysis, the horse, the saddle or the rider could be measured. For further details on kinematic measurements and analysis the reader is referred to Clayton (2013).

\section{Kinematics of the Equine Gaits}

\subsection{The Walk}

The walk is a symmetrical gait that has a lateral sequence of hoof placements (left hind, left fore, right hind, right fore) and no suspension phases (Hildebrand, 1965; Clayton, 1995; Hodson et al., 1999). The four footfalls should be evenly spaced in time although the presence of lateral or diagonal couplets is not uncommon (Clayton, 1995; Hodson et al., 1999). During walking the head is raised and lowered twice in each stride. The head is high at forelimb contact and low around forelimb midstance. Head displacement is velocity-dependent with both maximal 
and minimal head heights being positively correlated with walking velocity (Khumsap et al., 2002). The thoracolumbar spine undergoes two cycles of flexion and extension per stride with the motion occurring earlier in the stride cycle in the more caudal segments and progressing cranially. The amplitudes of flexion-extension are smaller in the cranial vertebral segments and largest at the lumbosacral joint. There is a single cycle of lateral bending and axial rotation in each stride with similar patterns along the length of the thoracolumbar spine. Axial spinal rotation in each direction is maximal around the time of contact of the contralateral forelimb (Haussler et al., 2001). Lateral bending of the horse's back at walk is maximal around the time of ipsilateral hind hoof contact, i.e. bending of the horse's trunk to the left is maximal at left hind contact.

\subsection{The Amble}

There are a number of gaits, sometimes referred to collectively as ambling gaits, that are classified as walking gaits since there are no suspension phases. These gaits have the same footfall sequence as the walk but they vary in the absolute and relative temporal relationships between the footfalls; the rhythm of the footfalls may be evenly spaced, or they may occur as lateral or diagonal couplets depending on the gait (Nicodemus and Clayton, 2003). The ambling gaits are performed at faster speeds than the walk and, since there are no suspension phases, they are comfortable and easy for the rider to sit. The 3D movements of the horse's back have not yet been described for these gaits. In general, the head and neck are maintained in a fairly consistent, and often high, position, though the running walk is a notable exception in that it is distinguished by an exaggerated nodding motion of the head and neck (Nicodemus and Clayton, 2003). The tölt, which has been studied in more detail than the other ambling gaits, has temporal kinematics 
that classify it as a walking gait but the ground reaction forces of both fore- and hind limbs resemble those of trot in having a single force peak (Biknevicus et al., 2004). Tölting horses provide a smooth ride by avoiding suspension phases while maintaining energetic efficiency by using spring-mass mechanics in the hind limbs (Biknevicius et al., 2006). Thus, in reality the tölt is more similar to a leaping gait than a stepping gait (Starke et al., 2009).

\subsection{The Trot}

The trot is a symmetrical running gait in which movements of diagonal limb pairs are synchronized and suspension phases intervene between successive diagonal stance phases (Drevemo et al., 1980; Holmström et al., 1994; Clayton, 1994a). Dressage horses are trained to change stride length somewhat independently of stride duration and to make distinct transitions between four types of trot; in order of increasing speed these are the collected $(3.20 \pm 0.28 \mathrm{~m} / \mathrm{s})$, working $(3.61 \pm 0.10 \mathrm{~m} / \mathrm{s})$, medium $(4.47 \pm 0.23 \mathrm{~m} / \mathrm{s})$ and extended trots $(4.93 \pm 0.14 \mathrm{~m} / \mathrm{s})$ (Clayton, 1994a,). The duration of the suspension phases and the vertical range of motion increase with trotting speed (Clayton, 1994a) which implies higher vertical velocity of the centre of mass at the initiation of the suspension phases at faster speeds. The fact that the body is supported by a diagonal pair of limbs provides pitch and roll stability (Hobbs et al., 2014) and, consequently, pitching range of motion of the horse's back at trot is only about 4 degrees (Buchner et al., 2000). During the trot stride the entire horse rises vertically reaching its maximal height during or just before the suspension phase and sinks to its lowest point in the middle part of diagonal stance (Hobbs and Clayton, 2013). Flexion and extension of the horse's thoracolumbar spine (Robert et al., 2001) also contribute to the vertical excursions of the saddle and rider. The thoracolumbar spine flexes as the horse is pushing off in late diagonal stance and suspension, 
then extends during the first half of the next diagonal stance phase. Flexion is controlled by the epaxial musculature, including longissimus dorsi muscles, which are active during the suspension phases. Extension is controlled by the hypaxial muscles including rectus abdominis which are active during the middle part of diagonal stance (Robert et al., 2001). These patterns are consistent with the back movements being driven by locomotor forces under the control of muscular forces that act primarily to stabilize the spine rather than to increase its range of motion. As trotting speed increases, the abdominal and epaxial muscles are activated earlier in the stride and contract with greater intensity indicating that their action is to further stiffen the spine at faster speeds (Robert et al., 2001). Compared with the walk, the trot has a lower amplitude of thoracolumbar flexion-extension relative to the amplitude of lateral bending and axial rotation at all spinal levels. Lateral bending in the cranial thoracic region is out of phase with lateral bending at the lumbosacral joint. Maximal axial rotation coincides with contact of the ipsilateral forelimb (Haussler et al., 2001). The head and neck undergo small vertical excursions relative to the trunk in the trot; these are due to the effects of gravity on the cantilevered head and neck segments rather than being a component of the mechanics of the gait (Clayton et al., 2011).

\subsection{The Canter}

The canter is an asymmetrical leaping gait in which the leading limbs are on the same side in the fore and hind pairs. The sequence of footfalls is trailing hind, leading hind and trailing forelimbs together, then leading forelimb. A suspension phase intervenes after lift off of the leading forelimb (Hildebrand, 1977; Clayton, 1994b) with the duration of the suspension and the associated vertical acceleration increasing with speed (Clayton, 1994b; 2004). The canter is 
characterized by having a rocking motion of the body as a consequence of the hind to front sequence of limb supports. The body axis tilts uphill (nose up) during the suspension and hind limb stance phases then becomes horizontal and even downhill (nose down) during the forelimb stance phases. The range of pitching motion of the trunk is around 8 degrees (Dunbar et al., 2008).

During canter the thoracolumbar spine undergoes a single cycle of flexion-extension in each stride. Maximal lumbosacral extension occurs at $25 \%$ of the stride cycle which is around the time of contact of the diagonal pair. Maximal flexion coincides with midstance of the leading forelimb and increases in amplitude with speed (Johnson and Moore-Colyer, 2009).

\subsection{The Gallop}

As cantering speed increases, contacts of the diagonal limb pair become dissociated resulting in a 4-beat rhythm in which the leading hind limb contacts the ground before the trailing forelimb. Data describing the forces between horse and rider (Geser-von Peinen et al., 2013) suggest that in the gallop the centre of mass undergoes smaller vertical oscillations than in the canter. As galloping speed increases a second suspension phase may intervene between lift off of the leading hind limb and contact of the trailing forelimb and, at extreme galloping speeds, there may be a very short third suspension between lift off of the trailing forelimb and contact of the leading forelimb (Seder and Vickery, 2003).

\section{Effect of the Saddle}

As the interface between horse and rider, the saddle has a large effect on equestrian performance. Although the saddle is attached to the horse's back, saddle movements and ranges of motion can 
be somewhat different to those of the horse's back because the relatively rigid construction of the saddle does not completely conform to changes in the horse's back shape. In addition, the presence of a rider may modify the movements of the saddle. Correct fitting of the saddle to the horse's back affects the consistency of the horse's stride; the horse's forward velocity, forward acceleration and transverse acceleration have lower variability when the horse is ridden at trot with a well-fitted saddle (Peham et al., 2001). A poorly fitting saddle interferes with communication between rider and horse, impairs mobility of the horse's back, and alters the regular, consistent pattern of the gait. The use of a saddle pad may improve the fit of a saddle that is basically the correct shape for the horse but not a perfect fit though Harman (1994) reported that only $35 \%$ of pads used for this purpose improved saddle fit or did not influence saddle fit in a negative way. Different pad materials vary in their effectiveness in damping total force on the horse's back at walk and trot (Kotschwar et al., 2010a, 2010b).

\section{Effect of the Rider}

The coupled system of rider and horse produces complex coordination patterns that can be used to distinguish between gaits and riding styles (Viry et al., 2013). Rider kinematics can be described and evaluated in terms of the movements of the axial body segments (head, trunk, pelvis) and the limbs (arms, legs). Each segment undergoes three-dimensional translations and rotations though not all of these have, as yet, been measured and reported. The rider's pelvis is particularly important since it has direct contact with the saddle so pelvic motion is crucial to a rider's success. During riding the pelvis primarily rotates (pitches) in the sagittal plane around a transverse axis. The direction of pelvic pitch is determined according to whether the upper part of the pelvis rotates posteriorly (positive pitch) or anteriorly (negative pitch) relative to the lower 
part (Figure 1). Pelvic roll occurs around the anteroposterior axis and is observed from in front or behind. Positive values correspond with the upper part of the pelvis rolling to the left around an anteroposterior axis. Pelvic yaw occurs around the vertical axis. Yaw rotation to the left occurs when the left side of the pelvis twists posteriorly (positive yaw).

Although the horse is, in general, responsible for driving the movement of the horse-rider combination, the rider can also have an effect on movements of the horse. The range of back motion of the horse is affected first by the presence of a rider and, second, by the riding technique. When weight is added to the horse's back, regardless of whether it is dead weight or the rider's weight, it causes extension of the thoracolumbar spine (hollowing of the horse's back) both when the horse is standing and during locomotion (De Cocq et al., 2004, 2009). During locomotion the range of back motion is the same with or without the additional weight but the entire cycle of movement is more extended with added weight. In sitting trot the effect of the rider's weight is equivalent on the two diagonals but in rising trot the kinematics of the horse's back resembles sitting trot on the sitting diagonal and an unloaded situation on the rising diagonal (de Cocq et al., 2010).

When dead weight is added to the horse's back, limb loading increases proportionally more in the forelimbs than the hind limbs (Schamhardt et al., 1991) but differences between carrying dead weight or a rider are minimal in terms of the horse's kinematics or energetics (Sloet von Oldruitenborgh-Oosterbaan et al., 1995). Interestingly, a horse and rider combination show differences in the shapes of the vertical ground reaction force curves (Clayton et al., 1999) so they are not equivalent to a proportionally larger horse.

The presence of a rider can also affect lameness patterns. Both the affected limb and the degree of lameness may change when horses are ridden versus trotted in hand and the effect of 
the rider cannot be predicted for an individual horse. In a study of 20 horses that had been assessed for lameness when trotting in hand, mean hind limb lameness score increased when they were ridden by an experienced dressage rider but not when ridden by a novice rider (Licka et al., 2004) due to the fact that the experienced rider was transferring weight to the haunches.

\section{Interaction between the Horse, the Saddle and the Rider in Different Gaits}

\subsection{The Walk}

In walk the movements of the horse's trunk, the saddle and the rider are repeated, but in opposite directions, in each half of the stride. In general, the movements of the saddle follow those of the horse's trunk though they may be modified by the presence of the rider. The rider's movements are clearly driven by the movements of the horse, but the rider can, conversely, influence the horse's movement pattern at walk. An interrelationship between horse and rider roll rotations is evident, as the roll rotation of the saddle is markedly slowed or temporarily reversed at the time when the horse's back and rider's pelvic rotation reverse in direction (Byström et al., 2010). Altering the position of the horse's head and neck during walking has also been found to influence the horse's movements substantially more than trotting (Rhodin et al. 2008).

The directions of pitch, yaw and roll of the horse's trunk change each time a hind hoof contacts the ground at walk. There are two pitching cycles per stride that reflect vertical motion of the croup relative to the withers. At hind hoof contact the croup is low and the trunk is maximally pitched in a nose up orientation. It pitches in a nose down direction as the croup rises in the first half of hind limb stance then reverses direction around the time of forelimb contact and pitches in a nose up direction until contact of the contralateral hind limb. The range of trunk pitching motion is 6.2 \pm 1.1 degrees for horses ridden by professional riders (Münz et al., 2014). 
The saddle follows the same pitching pattern as the horse's trunk (Galloux et al., 1994; von Peinen et al., 2009; Munz et al., 2014). At hind hoof contact it is maximally pitched with the pommel up, the front part of the saddle is unweighted and total force on the horse's back is at a minimum (von Peinen et al., 2009). As the croup rises during hind limb stance the rider sinks into the saddle and this coincides with the maximal total force. The range of pitching motion for the saddle is 6.1 \pm 0.9 degrees (Byström et al., 2010).

The rider's pelvis also undergoes two pitching cycles per walk stride during which the direction of rotation is opposite to the pitch of the saddle; the rider's pelvis pitches posteriorly from the time of hind limb contact to forelimb contact then pitches anteriorly from forelimb contact to the next hind limb contact. Byström et al. (2009) reported the range of pitching motion to be 9.7 \pm 2.0 degrees, whereas Münz et al. (2014) reported a range of $8.1 \pm 4.1$ degrees in beginner riders and $11.1 \pm 3.6$ degrees in professionals with the professionals maintaining greater posterior pitch throughout the stride. There does not appear to be a clear pattern of pitching motion of the rider's trunk. However, a study in which the pelvis and trunk were considered as a single rigid segment from hip to shoulder, described regular oscillations in rhythm with the walk stride from an average posterior tilt of 1.9 degrees at hind limb contact to an average anterior tilt of 2.8 degrees at forelimb contact (Lovett et al., 2005).

The horse's back, the saddle and the rider's pelvis undergo a single cycle of yaw and roll in each stride. When a hind limb lifts off, the horse's trunk and the rider's pelvis roll rapidly toward that limb, i.e. away from the weight-bearing hind limb. The ranges of motion in roll have been

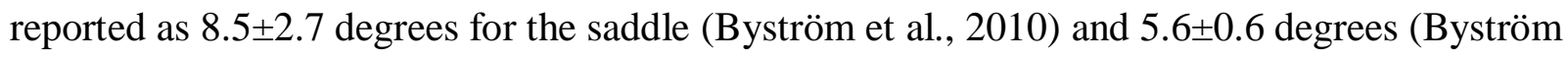
et al., 2010), and 5.3 \pm 1.2 degrees (Münz et al., 2014) for the pelvis of an experienced rider. The yaw motion is such that the front of the saddle and the rider's pelvis twist towards the weight- 
bearing hind limb with ranges of motion in yaw of $8.3 \pm 1.5$ degrees for the saddle and $8.2 \pm 1.9$ degrees for the rider's pelvis. Yaw motion of the rider's trunk is in the opposite direction to that of the pelvis with a range of motion of 5.0 \pm 1.3 degrees (Byström et al., 2010).

Beginner riders tilt the trunk anteriorly with greater flexion of the shoulder and elbow joints and a more forward leg position with greater extension of the knee and ankle joints when riding at walk. With experience the trunk becomes tilted slightly posteriorly (Kang et al., 2010). The walk shows significantly less predictability than the other gaits which adds to the rider's difficulty in achieving consistent control of the horse. Based upon the low correlation values between movement patterns of rider and horse, the walk appears to be a more difficult gait to ride than trot or canter (Wolframm et al., 2013). This finding is supported by the larger phase lag in walk supporting the notion of a looser synchronization of the rider with the horse.

\subsection{The Trot}

The trot stride includes suspension phases and the rider must learn to accommodate the resulting vertical perturbations in order to ride in harmony with the horse and avoid bouncing against the saddle and the horse's back. The horse's trunk pitches in a nose up direction during the first half of diagonal stance and pitches nose down in the second half of diagonal stance. Similarly, the saddle has two pitching cycles per stride with the pommel pitching up in the first half of each diagonal stance phase and down in the second half of diagonal stance through a range of motion of 5.6 \pm 0.6 degrees (Byström et al., 2009). Yaw and roll movements of the saddle have a single cycle per trot stride that follows the corresponding rotations of the horse's tenth thoracic vertebra (T10) as described by Faber et al. (2001). The pommel is maximally twisted towards the hind limb as it contacts the ground and rotates towards the opposite hind limb during the following 
stance and suspension phases. At the start of diagonal stance the tuber coxae of the contacting hind limb is at its maximal height and the saddle is maximally rolled away from that hind limb. The saddle rolls towards the weight-bearing hind limb throughout its stance phase and reverses direction just before it leaves the ground. The range of motion for saddle roll is $7.3 \pm 5.2$ degrees (Byström et al., 2009).

The rider can adopt different strategies (sitting, rising, two-point) to accommodate the horse's motion at trot, which involve adjustments in the stiffness of the body spring (De Cocq et al., 2013). In sitting trot the rider remains seated in the saddle throughout the stride with the midline body segments moving to accommodate the horse's motion. Peak forces in the saddle are higher in sitting trot than in rising trot in which the rider alternately rises out of the saddle and sits into the saddle on the two diagonals. Peak force on the saddle is lower on the rising diagonal compared with the sitting diagonal, and both diagonals at rising trot have a lower peak vertical force than sitting trot (Peham et al., 2010; De Cocq et al., 2010). The discrepancy in forces between the sitting and rising diagonals indicates that the rider should change the rising diagonal periodically. In a standing trot or two-point position, the rider's weight is supported by the stirrups and the seat is above the saddle throughout the stride. Vertical motion of the horse is absorbed using flexions of the hip and knee joints. This has the effect of reducing peak vertical force by spreading the forces more evenly throughout the stride (Peham et al., 2010). Regardless of technique, however, the total force averaged over the entire trot stride is close to the rider's body weight and it does not change with rider technique, rather it is redistributed at different times in the stride (de Cocq et al., 2010). In a mechanical simulation of different trotting techniques, in order to perform rising trot the rider's body required a relatively low spring stiffness combined with a high damping coefficient. The simulation indicated that the rider had 
to expend more energy during rising trot than during sitting trot or the two-point position (De Cocq et al., 2013).

The different rider positions at trot also affect the rider's stability relative to the saddle and the horse's back. This has been measured by tracking the position of the rider's centre of pressure (point of balance) during the stride using a pressure mat. The longitudinal range of motion of the rider's centre of pressure was significantly highest in sitting trot, significantly lowest in a two-point position and intermediate in rising trot with the rising trot values being significantly different from both of the other positions. Notably, the position of the centre of pressure did not move toward the withers in the two-point position. Lateral movement of the centre of pressure did not differ between rider strategies (Peham et al., 2010).

\section{3. $\quad$ Sitting Trot}

The majority of equestrian kinematic studies have focused on the sitting trot in which the vertical and horizontal accelerations of the horse's trunk are responsible for the movements of the rider. The rider's body is stiffened by muscular contractions to resist impact forces that tend to cause the body to collapse (Terada et al., 2004). The deceleration phase, which coincides with the first half of diagonal stance, is characterized by the rider pressing forward and downward against the saddle as the rider's legs and head move forwards. The rider's back hollows and the leg joints flex to absorb the deceleration. In the second half of diagonal stance the horse's trunk is accelerated forward and upward which pushes the rider out of the saddle and unweights the horse's back. The rider's head and legs move backward, the leg joints extend and the lumbar lordosis flattens out (Byström et al., 2009). 
Changes in direction of the rider's body motion coincide with the start of the diagonal stance phases (Byström et al., 2009). The pelvis is the rider's direct point of contact with the saddle and its rotations are temporally related to those of the saddle with a consistent pattern between riders. The rider's pelvis pitches in the opposite direction to the saddle; it pitches anteriorly during the first half of diagonal stance, which increases the lumbar lordosis (hollows the back), and pitches posteriorly during the second half of stance, which flattens the lumbar lordosis (rounds the back) with the maximal value for anterior pitching occurring during the suspension phase. The range of motion for pelvic pitching in experienced riders has been

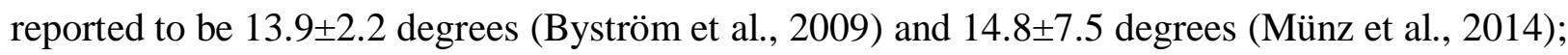
professional riders show about 2 degrees greater posterior pelvic pitch throughout the stride compared with beginners (Münz et al., 2014). When the rider is actively influencing the horse to collect the trot stride, the pelvis shows significantly greater posterior pitch throughout the stride (Byström et al., 2015; Engell et al., 2016). The force between the rider and the saddle increases to a maximum in mid-stance which corresponds with the time of maximal hollowing of the rider's back. The horse's trunk then starts to rise, pushing upwards against the rider's seat as the pelvis pitches posteriorly.

Overall, experienced riders maintain the trunk in an orientation close to the vertical (Schils et al., 1993; Terada et al., 2006; Kang et al., 2010). The trunk tends to pitch in counter rotation to and with a smaller range of motion than the pelvis (Byström et al., 2009). The oscillation pattern is more regular in an expert rider compared with a novice, and the expert is able to sit more deeply to absorb the horse's vertical motion whereas the novice sits straighter and experiences more jarring as the horse bounces up and down (Lagarde et al., 2005). In a majority of riders the trunk pitches posteriorly in early diagonal stance and anteriorly in late diagonal stance through a 
range of around 10.7 \pm 3.4 degrees (Byström et al., 2009). The net effect of these movements is to exaggerate the lumbar lordosis in midstance and to reduce it in the suspension phase. However, there are inter-individual differences in both the magnitude and direction of trunk pitch (Alexander et al., 2015; Engell et al., 2016) and in the relative amounts of motion of the rider's shoulders and hips. A majority of experienced riders have relatively less motion of the shoulders compared with the hips, which implies that hip motion is used to stabilize the shoulder. However, a few riders show an opposite pattern (Terada et al., 2006).

The rider's head pitches through a relatively large range of motion of $15.7 \pm 4.5$ degrees (Byström et al., 2009) and there is considerable inter-rider variability in the magnitude and direction of head rotation (Engell et al., 2016).

The rider's pelvic yaw motion follows that of the saddle. The pelvis is maximally twisted towards the hind limb as it contacts the ground then rotates in the opposite direction throughout the diagonal stance phase until it is maximally twisted in the opposite direction at the next hind limb contact. A greater range of yaw rotation has been reported for the rider's pelvis $(7.9 \pm 2.1$ degrees) compared to the saddle (5.7 \pm 1.0 degrees; Byström et al., 2009).

Yaw rotation of the rider's trunk is opposite to that of the pelvis. The trunk is maximally twisted away from the hind limb at contact, but then twists towards this limb during the first half of diagonal stance and maintains that position until the subsequent diagonal contact. The range of trunk motion in yaw has been reported to be 5.5 \pm 1.1 degrees (Byström et al., 2009); and in that study the trunk rolled to the left during both diagonal stance phases.

The rider's pelvic roll, in general, is out of phase with that of the horse's trunk and the saddle. The pelvis is maximally rotated towards the hind limb that is contacting the ground, then rolls away from this limb throughout its stance phase and the following suspension. In 
experienced riders the range of pelvic rolling motion has been reported as $5.1 \pm 1.1$ degrees (Byström et al., 2009) and as 4.1 \pm 1.0 degrees (Münz et al., 2014) with professional riders showing significantly less roll of their own pelvis and of the horse's trunk compared with beginners (Münz et al., 2014). Roll rotation shows some individual variation in its rate and direction in the second half of diagonal stance and is sometimes asymmetrical on the left and right sides (Byström et al., 2009) which may reflect asymmetrical pushing forces from the horse's left and right hind limbs. The rider's pelvis and trunk roll in opposite directions (Münz et al., 2014).

In the first half of diagonal stance the rider's hip joints flex and abduct and the knee joints flex and adduct. The rider's toes move anteriorly and laterally relative to the rider's hips and the heels are lowered relative to the toes. These movements are reversed in the second half of stance (Byström et al., 2009). Movements of the heel and toe are more tightly synchronized in expert riders who use ankle flexion to damp the vertical oscillations of the horse, whereas the ankle tends to be more still and stiff in novice riders (Lagarde et al., 2005).

Coordinated movements of the rider's shoulder and elbow joints allow the wrist to maintain a consistent position relative to the bit in spite of the movements of the axial body segments (Terada et al., 2006). The upper part of the rider's trunk oscillates back and forth twice per stride. The shoulders are furthest from the bit at the beginning of the diagonal stance phases when the trunk has a posterior pitch and the shoulder and elbow joints are extended. As the trunk pitches forwards in late stance, the shoulder and elbow joints extend (Terada et al, 2006; Byström et al., 2009). As a result of these synchronized movements, the distance between the rider's wrist and the nearest part of the bit rings to which the reins are attached changes by only $15 \pm 3 \mathrm{~mm}$ during the stride (Terada et al., 2006). In expert riders the shoulder, elbow and wrist 
oscillate synchronously whereas less experienced riders show a progressively larger delay from proximal to distal joints accompanied by an increase in relative phase variability (Lagarde et al., 2005).

When actively influencing the horse to move with greater collection, that is with shorter, more elevated strides, all riders show increased posterior pelvic rotation during diagonal stance (Byström et al., 2015; Engell et al., 2016). Mean values for the rotations of the trunk and head segments indicate a general pattern in which both segments pitch posteriorly during diagonal stance but there is greater variability between riders in both the magnitude and direction of rotation for these segments compared with the pelvis. This is thought to be indicative of individualized rider strategies (Engell et al., 2016).

Stirrup forces at sitting trot show two peaks per stride with the values being asymmetrical for the ipsilateral and contralateral diagonals, which showed peak values of $0.45 \pm 0.05$ and $0.39 \pm 0.05$ (N/N body weight of rider) (van Beek et al., 2012). Note that the units are standardized as stirrup force in Newtons per Newton of rider body mass (N/N). Unfortunately, data were reported only from one stirrup so it was not possible to compare values recorded synchronously on the two sides. The left-right asymmetry in peak values may be associated with a left-right shift in the rider's centre of pressure (Fruewirth et al., 2004) as a consequence of the pelvic roll away from the grounded hind limb. The peaks were found to occur at a fundamental frequency of $2.6 \mathrm{~Hz}$, which corresponds with the diagonal step frequency of the horse, that is, the timing of foot strike of each diagonal step (van Beek et al., 2012). An additional harmonic, known as the first harmonic, was found at around $5.2 \mathrm{~Hz}$, so a smaller peak was also evident in between each diagonal step. This is not surprising since harmonics are often present in 
complicated mass-spring systems such as the horse-rider system and may represent, for example, flexions of the rider's ankle joints that dampen the vertical forces (Lagarde et al., 2005).

The motion of the horse's trunk drives the kinematic, kinetic and muscular activation pattern of the rider, but these patterns will also vary with the rider's skill level. Compared with novices, advanced riders have a more vertical trunk (Schils et al., 1993; Lagarde et al., 2005) with the thigh and lower leg more retracted, which results in a more extended hip angle, and the arm is carried further ahead of the trunk (Schils et al., 1993). Novice riders show noticeable anterior-posterior instability of the trunk (Terada, 2000) in response to the relatively large changes in longitudinal forces and speed during the trot stride (Hobbs and Clayton, 2013). With experience riders learn to adjust their kinematics in anticipation of the horse's movements in a feed forward mechanism (Terada et al., 2006). The relative phase between horse and rider captures the overall spatiotemporal organization of the horse-rider system and the rider's ability to coordinate with the horse's dynamics requires considerable training and practice (Lagarde et al, 2005).

The electromyographic frequency distribution of rectus abdominis and erector spinae muscles suggests that novice riders are unable to balance their own muscular activities to stabilize the spine. Instead novice riders activate adductor magnus to stabilize the body. The resulting instability is reflected in the acceleration profile of the rider's head. Advanced riders have more similar levels of activity in rectus abdominis and erector spinae with hardly any activity in adductor magnus (Terada, 2000). Activity of the rider's rectus abdominis in the middle part of diagonal stance (Terada et al., 2006) may contribute to both posterior pelvic pitching and anterior thoracic pitching. 
The rider's ability to anticipate and accommodate the horse's movements affects the phase relationship between horse and rider. Expert riders have a more consistent motion pattern and move in a closer phase relationship with the horse whereas an unskilled rider disturbs the motion pattern consistency. The effect of an expert rider is manifest as reduced variability of forward velocity and acceleration which makes the horse's stride more consistent and less variable (Peham et al., 2001; Legarde et al., 2005). The tight synchronization between an expert rider and the horse results in greater regularity of the oscillations of the horse's trunk whereas novice riders allow transient departures from phase synchrony (Lagarde et al., 2005). A professional rider is more highly adapted to the horse's movement pattern and is able to control the horse's head angle more consistently than a recreational rider by imposing a rider-specific motion pattern that is repeated on a stride-by-stride basis (Schöllhorn et al., 2006). Locomotor stability of the horse improves when ridden by an expert rider (Peham et al., 2001; Lagarde et al., 2005; Schöllhorn et al., 2006).

Compared with canter, the movement coordination pattern of rider and horse is less tightly synchronized at trot and phase lag between rider and horse is significantly greater (Wolframm et al., 2013). Interestingly, horse-rider coordination dynamics do not markedly improve within a training session and are not affected by the direction of travel.

\subsection{Rising trot}

Kinematics of the rising trot are atypical in that the rider's pelvis pitches in the same direction as the horse's trunk. Pelvic roll motion in rising trot is similar in magnitude and direction to sitting trot (Münz et al., 2013). Stirrup forces in rising trot show two peaks per stride with significantly different values for the diagonal in which the rider rises out of the saddle $(1.17 \pm 0.06 \mathrm{~N} / \mathrm{N})$ versus 
the diagonal on which the rider sits in the saddle $(0.33 \pm 0.03 \mathrm{~N} / \mathrm{N})$. Amplitude spectra analysis indicated prominent peaks at $2.6 \mathrm{~Hz}$ corresponding with the diagonal step frequency and at 1.3 $\mathrm{Hz}$ representing the frequency of the rider standing in the stirrup (van Beek et al., 2012).

In rising trot the ankle joint was plantar-flexed in beginners but dorsi-flexed in advanced riders (Kang et al., 2010). Novice riders showed coactivation of rectus abdominis and iliocostalis lumborum which is energetically expensive. More experienced riders show a phase shift between these two muscles with rectus abdominis acting as an agonist by initiating its contraction as the rider makes contact with the saddle and continuing to contract through the period of lumbosacral flexion (Pantall et al., 2009). Both muscles showed synergistic activity on the left and right sides. Older riders appeared less able to activate rectus abdominis independent of iliocostalis to produce trunk flexion.

\subsection{Two Point Trot}

The two point trot is used extensively during endurance racing and this is justified on the basis of the lower peak vertical forces on the horse's back compared with the rising trot or sitting positions (Peham et al., 2010). The rider's weight is borne by the stirrups without contact of the rider's seat with the saddle and the rider's body undergoes only a small amplitude of motion vertically or longitudinally. The relatively small amplitude of longitudinal displacement in the two point position allows it to be distinguished from rising trot using accelerometric data (Viry et al., 2013). However, the degree of muscular activity required to coordinate movements of the rider's legs, arms and trunk in the two-point position is thought to engender a higher metabolic cost for the rider. 


\subsection{The Canter}

The canter is characterized by having a larger range of pitching motion of the horse's trunk (15.7 \pm 2.3 degrees) than walk or trot (Münz et al., 2014). The horse's trunk pitches in a nose up direction during the suspension and trailing hind limb stance phase then reverses direction around the time of diagonal contact. The rider's pelvis pitches out of phase with the horse's trunk through a range of 18.0 05.0 degrees (Münz et al., 2014). The horse's trunk rolls toward the side of the trailing limb during its stance phase, reverses direction and rolls towards the side of the leading limbs through the diagonal stance phase, then reverses direction again around the time of leading forelimb contact. The range of roll rotation of the horse's trunk is $7.0 \pm 1.6$ degrees. The rider's pelvis rolls in the opposite direction to the horse's trunk throughout the stride through a range of 5.9 \pm 1.5 degrees (Münz et al., 2014). Yaw rotation of the rider's trunk in canter is greater than in the other gaits (Symes and Ellis, 2009). The rider's combined pelvis/trunk segment has an anterior inclination throughout the stride with the degree of inclination increasing from contact of the trailing hind limb to contact of the leading forelimb (Lovett et al., 2005).

The canter is easier to sit than the trot as a consequence of having smaller longitudinal accelerations and decelerations within the stride and riders are better coordinated with the horse's movements in canter without having to resort to inappropriate muscle activation patterns (Terada, 2000). Furthermore, the coordination dynamics of canter and the consistency of the strides allow higher levels of horse-rider synchronicity and coordination compared with walk or trot (Wolframm et al., 2013).

Endurance riders often use the two point canter which can be differentiated from the sitting canter on the basis that the rider's body undergoes a smaller amplitude of motion in a longitudinal direction (Viry et al., 2013). 


\subsection{The Gallop}

The riding style used most frequently during galloping is the two-point seat which becomes the crouched jockey seat when the stirrups are very short. Energy savings are realized by uncoupling the rider's movements from those of the horse so the rider undergoes smaller movements in the world inertial frame than the horse. This is achieved by flexing and extending the joints in the rider's legs in rhythm with the vertical oscillations of the horse's trunk. This attenuates the rider's acceleration and deceleration in every stride. These movements involve considerable mechanical work, however, and are energetically expensive for the rider. The horse supports the rider's weight but energy expenditure is decreased because the horse does not have to accelerate and decelerate the rider in each stride cycle (Pfau et al., 2009).

\section{Rider Asymmetries}

Asymmetries in rider kinematics have been reported in several studies. Asymmetries may arise as a consequence of structural differences in anatomical dimensions or inherent laterality, or they may be acquired due to functional or dynamic differences or through habitual avoidance of painful movements. Regardless of their cause, the asymmetries may be exacerbated by repetition. Asymmetries in the position or movements of the rider change the loading pattern on the horse's back and can alter the movements of the horse (Licka et al., 2004; Nevison and Timmis, 2013).

Leg length inequality is a common anatomical finding in people with the right leg more often being shorter (Knutson, 2005) but its relationship to postural asymmetries in the rider is controversial. In one study, all riders were found to have a shorter right leg with the leg length asymmetry being correlated with shoulder rotation during riding (Symes and Ellis, 2009). On the 
contrary, a study of postural and functional asymmetries of riders with stratification by years of experience and competitive level (Hobbs et al., 2014) failed to find a discrepancy in leg lengths. This study also suggested that the demands on dressage riders competing at higher levels may contribute to the development of asymmetries rather than improving the rider's symmetry.

Awareness of the importance of defective rider posture, strength or technique is evident from the growing body of literature in these areas (Symes and Ellis, 2009; Blokhuis et al., 2014; Hobbs et al., 2014; Gandy et al., 2014; Alexander et al., 2015). Alexander et al. (2015) reported that eight out of ten riders presented with simultaneous asymmetrical rotation and lateral flexion of the trunk when riding in a straight line. The majority of the right-handed riders in that study presented with a right pelvic roll and left trunk roll which, in combination, resulted in a collapsed left hip. In addition the pelvis and trunk were rotated to the right so the right shoulder was relatively retracted. Other studies have reported asymmetric rider kinematics of the trunk and head segments in yaw and roll (Byström et al., 2009) and in the rider's thoracic girdle (Symes and Ellis, 2009). In the latter study the riders trunk was rotated to the left and showed significantly greater angular displacement of the right shoulder at all gaits except right lead canter in which the two shoulders showed equivalent amounts of rotation.

Positional asymmetries translate into asymmetrical forces being applied to the saddle and the horse. When a group of riders sat on a pressure mat positioned on top of a static saddle, asymmetries of the rider were shown by higher pressure on the right side (Nevison and Timmis, 2013). Asymmetries of the rider's limbs have received less attention but Gandy et al. (2014) found differences of 1-27 degrees in mean external rotation angles of the left and right hip joints and with greater rotation of the right leg in $83 \%$ of riders (Gandy et al., 2014). 
Although the importance of a correct position and body mechanics in the rider is well recognized, subjective assessment of positional faults appears to be difficult. When a panel of 5 experienced judges and trainers evaluated 60 horse and rider combinations according to the presence of 16 postural deviations there was no statistical agreement between the assessments (Blokhuis et al., 2014). Apparently each panel member had 'favourite' deviations that they recorded relatively frequently. Overall, the most common rider faults identified by the judges involved the seat (unbalanced, unstable, stiff), the thighs (gripping up, clamping), or the knees (gripping).

Physiotherapeutic interventions address sensory or motor disturbances with the goal of improving functional performance. Nevison and Timmins (2014) investigated the effect of manual therapy focusing on the pelvic musculature with the effects being assessed by monitoring mediolateral displacements of the center of pressure while sitting on a force plate and by comparing values recorded by an electronic pressure mat (peak pressure, mean pressure, maximum force, contact area) while the rider was sitting in a normal riding posture on a static saddle horse model. The interventions were tailored to each rider's individual needs as determined by the physiotherapist with the goals of improving pelvic symmetry and motor control. The results showed a significant reduction of postural instability when seated on a force plate with arms crossed and legs still but above the ground and a redistribution of contact area of the saddle when sitting on a static saddle horse so that the right bias observed pre-treatment was no longer present.

Athletic taping can provide both mechanical support and proprioceptive effects that have applications in improving posture and for retraining correct muscular activation patterns in rehabilitation. A common postural problem for riders is rounding the shoulders (thoracic 
kyphosis). A postural taping technique (Watson's strap) that applies scapular retraction to reposition the scapula and thoracic spine into a neutral position resulted in a small, but statistically significant, increase in range of roll motion of the trunk (Alexander et al., 2015. This was interpreted as being due to an increase in lumbar motion that was compensating for passive reduction in thoracic kyphosis. The authors suggested that if tape is used to correct spinal posture during riding, then the strength of the tape and the taping method should be carefully considered to ensure that the mechanical changes do not over-stiffen the spine and induce unwanted compensatory motions.

\section{Conclusions}

Biomechanical studies of the interaction between horse and rider is an area of active and growing research interest. This review has summarized the characteristics of equine gaits that affect the rider's position, movements and forces and has compared these characteristics across different equine gaits.

Many of the studies performed to date have been based on small numbers of subjects and the results have, perhaps, been over-interpreted. In order to establish normative ranges and to determine common asymmetries and their relationship to handedness patterns requires data from larger populations. A preliminary investigation of subjective assessment of rider technique and the detection of performance deficits suggests that it is difficult for trained equestrians to perform consistent evaluations. The use of objective research methods is necessary not only to establish normative ranges but also as a basis for providing empirical data that can be used to improve the observational skills of trainers and judges with regard to the detection and correction of faults in performance. Investigations of the value of interventional techniques to improve the performance 
of horses and riders should yield useful and practical information. Future efforts to further our knowledge of the horse-rider interaction through advancements in knowledge and understanding of equitation science can be expected to have a positive impact on horse welfare.

\section{Conflict of interest statement}

None

\section{Acknowledgements}

Not applicable 


\section{References}

Alexander, J., Hobbs, S.J., May, K., Northrop, A., Brigden, C. and Selfe, J. 2015. Postural characteristics of female dressage riders using 3D motion analysis and the effects of an athletic taping technique: A randomised control trial. Physical Therapy in Sport 16, 154-161.

Biewener, A.A. 2006. Patterns of mechanical energy change in tetrapod gait: pendula, springs and work. Journal of Experimental Zoology Part A Comparative Experimental Biology 305, 899911.

Biknevicius, A.R., Mullineaux, D.R. and Clayton, H.M. 2006. Locomotor mechanics of the tölt in Icelandic horses: Taking the walk for a run. American Journal of Veterinary Research 67, 1505-1510.

Blokhuis, A.Z., Aronsson, A., Hartmann, E., Van Reenen, C.G and Keeling, L. 2014. Assessing the rider's seat and horse's behavior: Difficulties and perspectives. Journal of Applied Animal Welfare Science 11, 191-203.

Buchner, H. H. F., Obermüller, S. and Scheidl, M. 2000. Body centre of mass movement in the sound horse. Vet. J. 160, 225-234. 
Byström, A., Rhodin, M., von Peinen, K., Weishaupt, M.A., and Roepstorff, L., 2009. Basic kinematics of the saddle and rider in high-level dressage horses trotting on a treadmill. Equine Veterinary Journal 41, 280-284.

Byström, A., Rhodin, M., von Peinen, K., Weishaupt, M.A., and Roepstorff, L., 2010. Kinematics of saddle and rider in high-level dressage horses performing collected walk on a treadmill. Equine Veterinary Journal 42, 340-345.

Byström, A., Roepstorff, L., Geser-von Peinen, K., Weishaupt, M.A., Rhodin, M. 2015. Differences in rider movement pattern between different degrees of collection at the trot in highlevel dressage horses ridden on a treadmill. Human Movement Science 41, 1-8.

Clayton, H.M. 1994a. Comparison of the stride kinematics of the collected, working, medium, and extended trot. Equine Veterinary Journal 26, 230-234.

Clayton, H.M. 1994b. Comparison of the collected, working, medium, and extended canters. Equine Veterinary Journal Supplement 17, 16-19.

Clayton, H.M. 1995. Comparison of the stride kinematics of the collected, medium, and extended walks in horses. American Journal of Veterinary Research 56, 849-852.

Clayton, H.M. 2004. The dynamic horse. Sport Horse Publications, Mason, MI. 
Clayton, H.M. 2013. Measurement techniques for gait analysis. In: Equine Locomotion, 2nd edition. Eds W. Back and H.M. Clayton. Elsevier B.V., London. pp 31-60.

Clayton, H.M., Lanovaz, J.L., Schamhardt, H.C. and Wessum, R. van. 1999. Rider mass effects on ground reaction forces and fetlock kinematics at the trot. Equine Veterinary Journal Supplement 30, 218-221.

Clayton, H.M., Larson, B., Kaiser, L.J. and Lavagnino, M. 2011. Length and elasticity of side reins affect rein tension at trot. The Veterinary Journal 188, 291-294.

De Cocq, P., Clayton, H.M., Terada, K., Muller, M. and van Leeuwen, J.L. 2009. Usability of normal force distribution measurements to evaluate asymmetrical loading of the back of the horse and different rider positions. The Veterinary Journal 181:266-273.

De Cocq, P., Duncker, A.M., Clayton, H.M., Bobbert, M.F., Muller, M. and van Leeuwen, J.L., 2010. Vertical forces on the horse's back in sitting and rising trot. Journal of Biomechanics 43: 327-631.s

De Cocq, P., Muller, M., Clayton, H.M. and van Leeuwen, J.L. 2013. Modelling biomechanical requirements of a rider for different horse-riding techniques at trot. Journal of Experimental Biology 216, 1850-1861. 
De Cocq, P., van Weeren, P.R. and Back, W., 2004. Effects of girth, saddle and weight on movements of the horse. Equine Veterinary Journal 36: 758-763.

Drevemo, S., Dalin, G., Fredricson, I. and Hjerten, G. 1980. Equine locomotion : 1 The analysis of linear and temporal stride characteristics of trotting Standardbreds. Equine Veterinary Journal $12,60-65$.

Dunbar, D.C., McPherson, J.M., Simmons, R.W. and Zarcades, A. 2008. Stabilization and mobility of the head, neck and trunk in horses during overground locomotion_comparisons with humans and other primates. Journal of Experimental Biology 211, 3889-3907.

Engell, M.T., Hernlund, E., Egenvall, A., Berg, A., Clayton, H.M., Roepstorff, L. 2016. Does foot pronation in unmounted horseback riders affect pelvic movement during walking. Comparative Exercise Physiology 11, 231-237.

Faber, M.J., Schamhardt, H., van Weeren, P.R., Roepstorff, L. and Barneveld, A. 1999. Determination of 3D spinal kinematics without defining a local vertebral coordinate system. Journal of Biomechanics 32, 1355-1358.

Faber, M., Johnston, C., Schamhardt, H., Van Weeren, R., Roepstorff, L. and Barneveld, A. 2001. Basic three dimensional kinematics of the vertebral column of horses trotting on a treadmill. American Journal of Veterinary Research 62, 757-764. 
Fruehwirth, B., Peham, C., Scheidl, M. and Schobeberger, H., 2004. Evaluation of pressure distribution under an English saddle at walk, trot and canter. Equine Veterinary Journal 36: 754757.

Galloux, P., Richard, N., Dronka, T., Leard, M., Perrot, A., Jouffroy, J.L. and Cholet, A. 1994. Analysis of equine gait using three-dimensional accelerometers fixed on the saddle. Equine Veterinary Journal Supplement 17, 44-47.

Gandy, E.A., Bondi, A., Hogg, R. and Pigott, T.M.C. 2014. A preliminary investigation of the use of inertial sensing technology for the measurement of hip rotation asymmetry in horse riders. Sports Technology DOI:10.1080/19346182.2014.905949

Geser-von Peinen, K., Latif, S.N., Wiestner, T., Bitschnau, C. Renk, B. and Weishaupt, M.A. 2013. Applied load on the horse's back under racing conditions. The Veterinary Journal 198, e88-e92.

Harman, J.C., 1994. Practical use of a computerized saddle pressure measuring device to determine the effects of saddle pads on the horses' back. Journal of Equine Veterinary Science $14,606-611$.

Haussler, K.K., Bertram, J.E.A., Gellman, K. and Hermanson, J.E. 2001. Segmental in vivo kinematics at the walk, trot and canter: a preliminary study. Equine Veterinary Journal Supplement 33, 160-164. 
Hildebrand, M. 1965. Symmetrical gaits of horses. Sci. 150, 701-708.

Hildebrand, M. 1977. Analysis of asymmetrical gaits. Journal of Mammalogy 158, 131-156.

Hildebrand, M. 1985. Walking and running. In Functional Vertebrate Morphology (ed.

Hildebrand, M., Bramble, D. M., Liem, K. F., Wake, D.B.), pp.38-57. Cambridge, London: Belknap Harvard.

Hobbs, S.J., Baxter, J., Broom, L., Dagg, L.-A., Sinclair, J.K. and Clayton, H.M. 2014. Posture, flexibility and grip strength in horse riders. Journal of Human Kinetics 42:113-125.

Hobbs, S. J. and Clayton, H. M. 2013. Sagittal plane ground reaction forces, centre of pressure and centre of mass in trotting horses. The Veterinary Journal Supplement 198, 1, e14-e19.

Hobbs, S.J., Richards, J. and Clayton, H.M. 2014. The effect of centre of mass location on sagittal plane moments around the centre of mass in trotting horses. Journal of Biomechanics 47 , 1278-1286.

Hobbs, S.J., Levine, D., Richards, J. Clayton, H.M., Tate, J. and Walker, R. 2010. Motion analysis and its use in equine practice and research. Wiener Tierärztliche Monatschrift Veterinary Medicine Austria 97, 55-64. 
Hodson, E.F., Clayton, H.M. and Lanovaz, J.L. 1999. Temporal analysis of walk movements in the Grand Prix dressage test at the 1996 Olympic Games. Applied Animal Behaviour Science 62, 89-97.

Holmström, M., Fredricson, I. and Drevemo, S. 1994. Biokinematic analysis of the Swedish Warmblood riding horse at trot. Equine Veterinary Journal 26, 235-240.

Johnson, J.M. and Moore-Colyer, L. 2009. The relationship between range of motion of lumbosacral flexion-extension and canter velocity of horses on a treadmill. Equine Veterinary Journal 41, 301-303.

Kang, O.D., Ryu, Y.C., Ryew,C.-C., Oh, W.-Y., Lee, C.-E. and Kang, M.-S. 2010. Comparative analyses of rider position according to skill levels during walk and trot in Jeju horse. Human Movement Science 29, 956-963.

Khumsap, S., Clayton, H.M., Lanovaz, J.L. and Bouchey, M. 2002. Effect of walking velocity on forelimb kinematics and kinetics. Equine Veterinary Journal Supplement 34, 325-329.

Knutson, G.A., 2005. Anatomic and functional leg-length inequality: a review and recommendation for clinical decision-making. Part I, anatomic leg-length inequality: prevalence, magnitude, effects and clinical significance. Chiropractic and Osteopathy 13, 11. 
Kotschwar, A.B., Baltacis, A and Peham, C., 2010a. The effects of different saddle pads on forces and pressure distribution beneath a fitting saddle. Equine Veterinary Journal, 42, 114-118.

Kotschwar, A.B., Baltacis, A and Peham, C., 2010b. The influence of different saddle pads on force and pressure changes beneath saddles with excessively wide trees. The Veterinary Journal, $184,322-325$.

Lagarde, J., Peham, C., Licka, T. and Kelso, J.A.S., 2005. Coordination dynamics of the horserider system. Journal of Motor Behavior 37: 418-424.

Licka, T., Kapaun, M. and Peham, C. 2004. Influence of rider on lameness in trotting horses. Equine Veterinary Journal 36, 734-736.

Lovett, T., Hodson-Tole, E. and Nankervis, K. 2005. A preliminary investigation of rider position during walk, trot and canter. Equien and Comparative Exercise Physiology 2, 71-76.

Malone, S.R. and Davies, H.M.S. 2015a. Yearling radiographic forelimb asymmetries and performance in Thoroughbred racehorses. . Journal of Equine Veterinary Science, 35, 394.

Malone, S.R. and Davies, H.M.S. 2015b. Distal forelimb asymmetries in the domestic horse. Journal of Equine Veterinary Science, 35, 426. 
Meij, H.S., Meij, J.C.P., 1980. Functional asymmetry in the motor system of the horse. South African Journal of Science 76, 552-556.

Münz, F., Eckardt, F., Heipertz-Hengst, C., Peham, C., Witte, K., 2013. A preliminary study of an inertial sensor-based method for the assessment of human pelvis kinematics in dressage riding. Journal of Equine Veterinary Science 33, 950-955.

Münz, A., Eckardt, F., Witte, K., 2014. Horse-rider interaction in dressage riding. Human Movement Science 33, 227-237.

Murphy, J., Sutherland, A., Arkins, S., 2005. Idiosyncratic motor laterality in the horse. Applied Animal Behaviour Science 91, 297-310.

Nevison, C.M. and Timmis, M.S. 2013. The effect of physiotherapy intervention to the pelvic region of experienced riders on seated postural stability and the symmetry of pressure distribution to the saddle: A preliminary study. Journal of Veterinary Behavior 8, 261-264.

Nicodemus, M.C. and Clayton, H.M. 2003. Temporal variables of four-beat, stepping gaits of gaited horses. Applied Animal Behavioural Science 80, 133-142.

Pantall, A., Barton, S. \& Collins, P. 2009. Surface electromyography of abdominal and spinal muscles in adult horse riders during rising trot. XXVII International Conference on Biomechanics in Sport. 17 - 21 August 2009. Limerick, Ireland. 
Peham, C., Licka, T., Kapaun, M., Scheidl, M., 2001. A new method to quantify harmony of the horse-rider system in dressage. Sports Engineering 4: 95-101.

Peham, C., Kotschwar, A.B., Borkenhagen, B., Kuhnke, S., Molsner, J. and Baltacis J., 2010. A comparison of forces acting on the horse's back and the stability of the rider's seat in different positions at the trot. The Veterinary Journal 184: 56-59.

Pfau, T., Spence, A., Starke, S., Ferrari, M. and Wilson, A. 2009. Modern riding style improves horse racing times. Science 325, 289.

Rhodin, M., Gómez Álvarez, C.B., Byström, A., Johnston, C., van Weeren, P.R., Roepstorff, L. and Weishaupt, M.A. (2008) The effect of different head and neck positions on the lumbar back and hind limb kinematics in the ridden horse. In: A Biomechanical Analysis of Relationship Between the Head and Neck Position, Vertebral Column and Limbs in the Horse at Walk and Trot, M. Rhodin, PhD Thesis, Swedish University of Agricultural Sciences, Uppsala, Sweden.

Robert, C., Valette, J.P. Poucelot, P., Audigié, F. and Denoix,, J-M., 2001. Effects of treadmill speed on the mechanics of the back in trotting saddlehorses. Equine Veterinary Journal Supplement 33, 154-159. 
Schamhardt, H.C., Merkens, H.W. and van Osch, G.J.V.M. 1991. Ground reaction force analysis of horses ridden at walk and trot. In: Equine Exercise Physiology 3. Ed. S.G.B. Persson, A. Lindholm and L.B. Jeffcott. ICEEP Publications, Davis, pp 120-127.

Schils, S.J., Greer, N.L., Stoner, L.J., Kobluk, C.N., 1993. Kinematic analysis of the equestrian walk, posting trot and sitting trot. Human Movement Science 12, 693-712.

Schöllhorn, W.L., Peham, C., Licka, T., Scheidl, M., 2006. A pattern recognition approach for the quantification of horse and rider interaction. Equine Veterinary Journal 36, 400-405.

Seder, J.A. and Vickery, C.E. 2003. Double and triple fully airborne phases in the gaits of racing speed Thoroughbreds. Journal of Equine Veterinary Science 23, Suppl 1, S73-S81.

Sloet van Oldruitenborgh-Oosterbaan, M.M., Barneveld, A. and Schamhardt, H.C. 1995. Effects of weight and riding on workload and locomotion during treadmill exercise. Equine Veterinary Journal 27, 413-417.

Starke, S.D., Robilliard, J., Weller, R., Wilson, A.M. and Pfau, T. 2009. Walk-run classification of symmetrical gaits in the horse: a multidimensional approach. Journal of the Royal Society Interface 6, 335-342.

Symes, D. and Ellis, R., 2009. A preliminary study into rider asymmetry within equitation. The Veterinary Journal 181: 34-37. 
Terada, K. 2000. Comparison of head movement and EMG activity of muscles between advanced and novice horseback riders at different gaits. Journal of Equine Science 11, 89-93.

Terada, K., Mullineaux, D.R., Kiyotada, K. and Clayton, H.M. 2004. Electromyographic activity of the rider's muscles at trot. Equine and Comparative Exercise Physiology 1, 193-198.

Terada, K., Clayton, H.M., Lanovaz, J.L. and Kato, K. 2006. Stabilization of wrist position during horseback riding at trot. Equine and Comparative Exercise Physiology 3, 179-184.

Viry, S., Sleimen-Malkoun, R., Temprado, J-J., Frances, J-P., Berton, E., Laurent, M., Nicol, C., 2013. Patterns of horse-rider coordination during endurance race: a dynamical system approach. DOI: 10.1371/journal.pone.0071804

Van Beek, de Cocq, P., Timmerman, M. and Muller, M. 2012. Stirrup forces during horse riding: A comparison between sitting and rising trot. The Veterinary Journal 193, 193-198.

Van Heel M.C., van Dierendonck, M.C., Kroekenstoel, A.M. and Back, W. 2010. Lateralised motor behaviour leads to increased unevenness in front feet and asymmetry in athletic performance in young mature Warmblood horses. Equine Veterinary Journal 42, 444-450. 
Von Peinen, K., Wiestner, T., Bogisch, S., Roepstorff, L., van Weeren, P.R. and Weishaupt, M.A. 2009. Relationship between the forces acting on the horse's back and the movements of rider and horse while walking on a treadmill. Equine Veterinary Journal 41, 285-291.

Watson, K.M., Stitson, D.J., Davies, H.M., 2003. Third metacarpal bone length and skeletal asymmetry in the thoroughbred racehorse. Equine Veterinary Journal 35, 712-714.

Wiggers, N., Nauwelaerts, S., Hobbs, S.J., Wolschrijn, C.F. and Back, W. 2015. Functional locomotor consequences of uneven forefeet for the trot of individual riding horses. PLoS ONE 10(2), e0114836. DOI: 10.1371/journal.pone.0114836.

Wolframm, I.A., Bosga, J. and Meulenbroek, R.G.J. 2013. Coordination dynamics in horse-rider dyads. Human Movement Science 32, 157-170. 


\section{Figure Captions}

Figure 1: Equine body axes and planes and associated terminology.

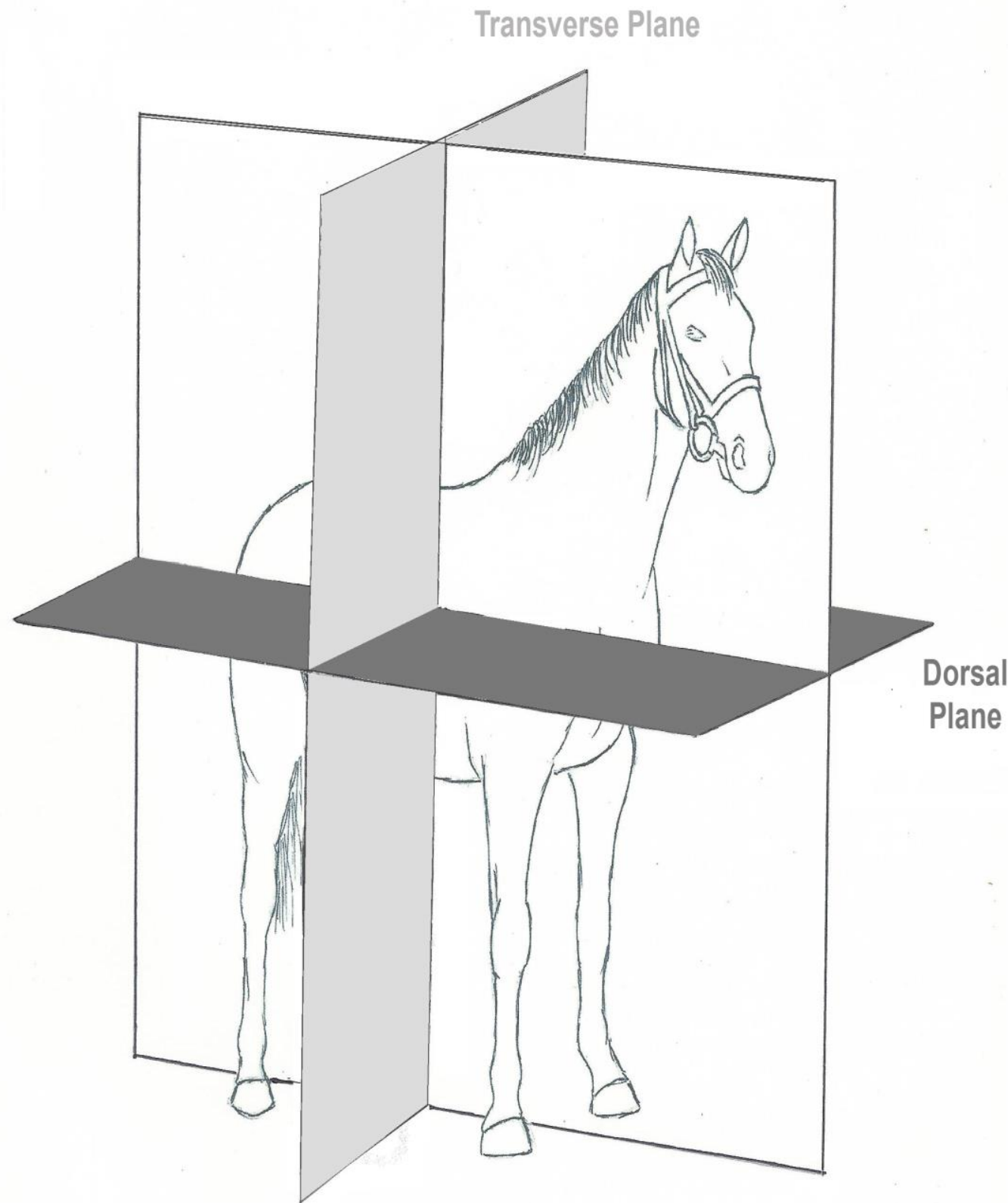

Sagittal Plane 


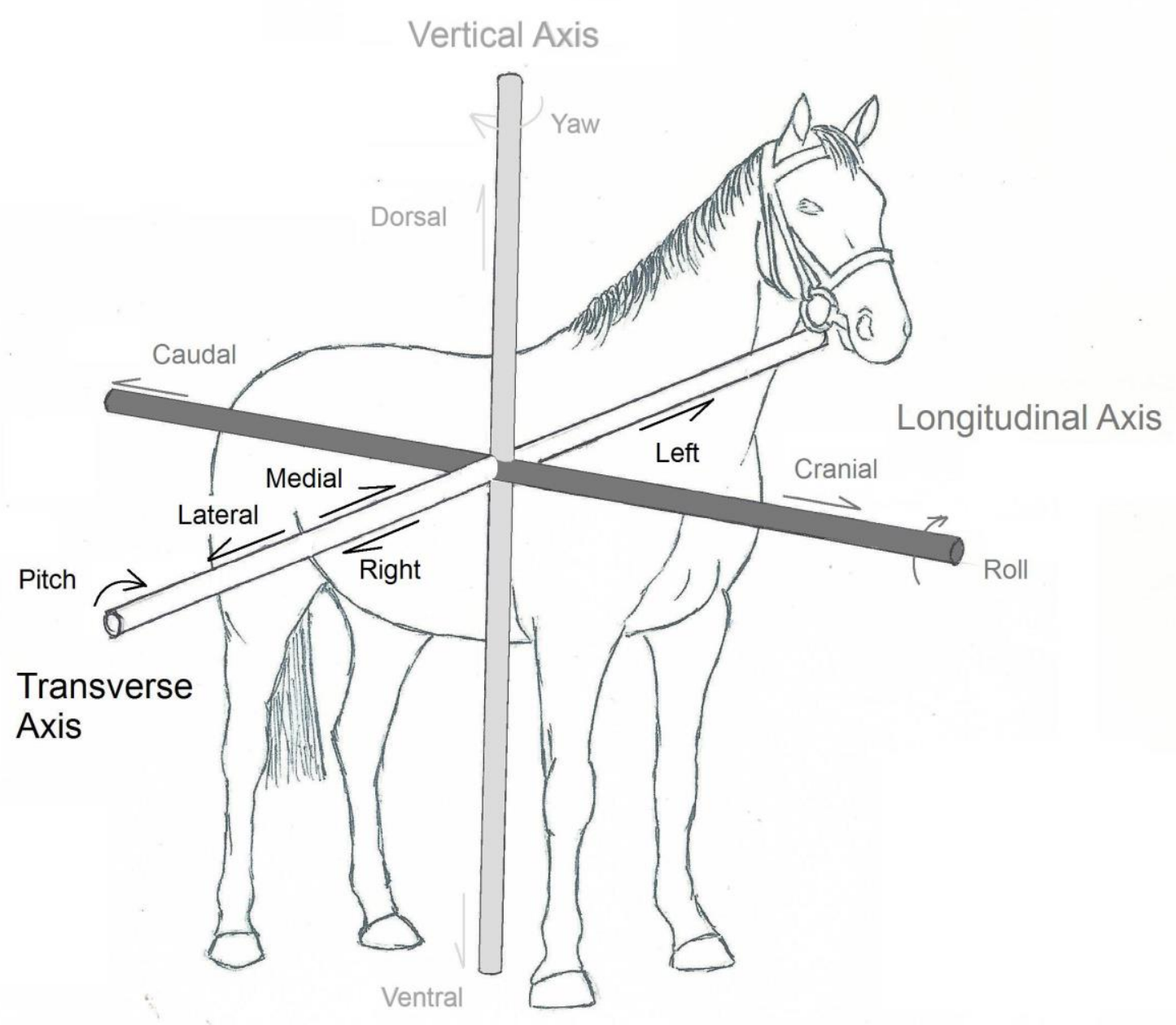


Figure 2: Human body axes and planes and associated terminology.

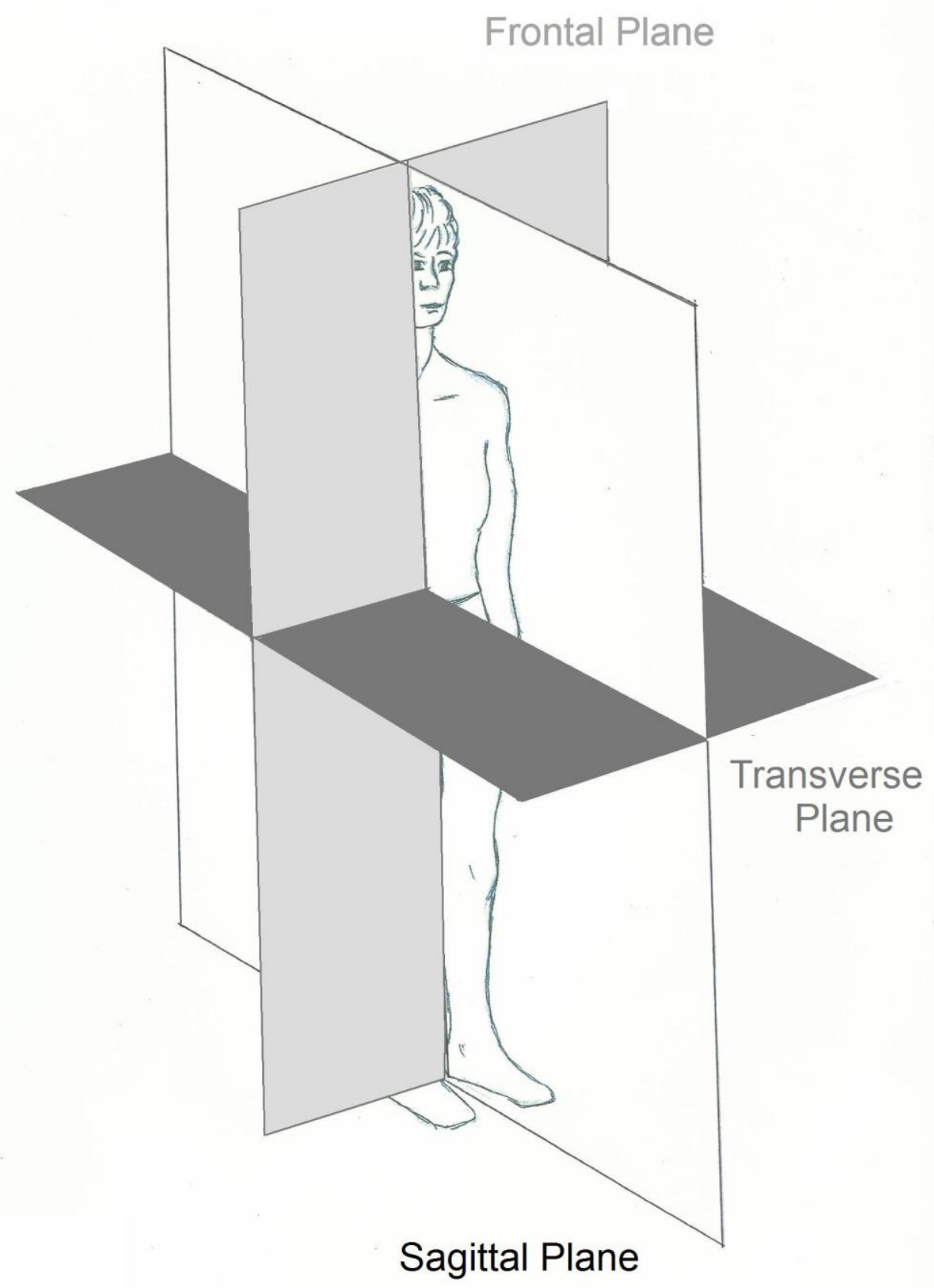




\section{Vertical Axis}

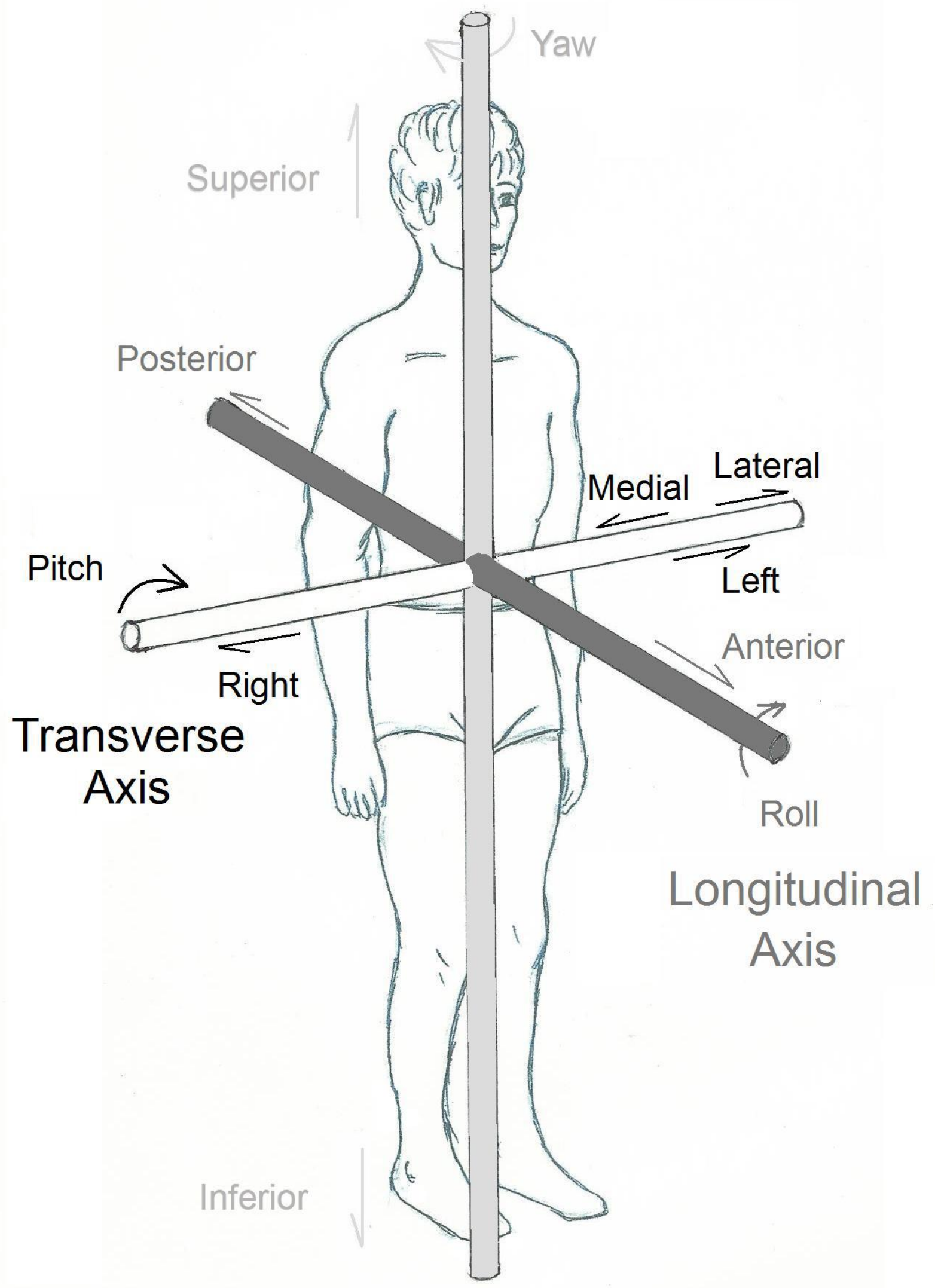

